University of New Haven

University of

New Haven

Digital Commons@ New Haven

Civil Engineering Faculty Publications

Civil Engineering

6-2014

\title{
Full-scale Experimental Modal Analysis of an Arch Dam: The First Experience in Iran
}

Reza Tarinejad

University of Tabriz

Mohammad Taghi Ahmadi

Tarbiat Modares University

Ronald S. Harichandran

University of New Haven, rharichandran@newhaven.edu

Follow this and additional works at: http://digitalcommons.newhaven.edu/civilengineering-facpubs

Part of the Civil Engineering Commons

\section{Publisher Citation}

Tarinejad, R., Ahmadi, M. T., and Harichandran, R. S. (2014). "Full-scale experimental modal analysis of an arch dam: the first experience in Iran.” Soil Dynamics and Earthquake Engineering, 61-62, 188-196. doi:10.1016/j.soildyn.2014.01.020

\section{Comments}

This is the authors' accepted version of the article published in Soil Dynamics and Earthquake Engineering. The version of record is available at http://dx.doi.org/10.1016/j.soildyn.2014.01.020 


\title{
Full-Scale experimental modal analysis of an arch dam, the first experience in Iran
}

\author{
Tarinejad, R., " Ahmadi, M. T., ${ }^{\text {b }}$ and Harichandran, R. S. \\ ${ }^{a}$ Faculty of Civil Engineering, University of Tabriz, Tabriz, East Azerbaijan Province, Iran \\ ${ }^{\mathrm{b}}$ Faculty of Civil Engineering, Tarbiat Modares University, Tehran, Iran \\ ${ }^{\mathrm{b}}$ Tagliatela College of Engineering, University of New Haven, New Haven, USA
}

\begin{abstract}
In this research forced vibration field tests, and finite-element studies have been conducted on Shahid Rajaee concrete arch dam (in Northern Iran) to investigate dynamic properties for the dam-reservoir-foundation system. The first forced vibration tests on the dam are performed with two available different types of exciter units, with low limited maximum force, bolted on the dam crest for alternative conditions of in-phase and out-of-phase cases. Because of an insufficient number of recording sensors two arrangements of sensors are used to cover sufficient points on the dam crest and one gallery during tests. Two kinds of vibration tests, On-off and frequency sweeping, are carried out on the dam. The primary natural frequencies of the coupled system for both symmetric and anti-symmetric vibration modes are approximated during on-off tests in two various circumstances of exciters, in phase and out-of-phase, with maximum frequency equal to $14 \mathrm{~Hz}$. The principal forced vibration tests are scheduled to precise resonant frequencies based on the obtained results of the on-off tests in which sweeping around the approximated frequencies with $0.1 \mathrm{~Hz}$ step is performed. Baseline correction and suitable bandpass filters are applied to the test records and then signal processing is carried out using PSD, CSD and Coherence Spectra by Fourier's transformation. Nine middle modes of the vibration of coupled system and corresponding damping ratios achieved by the particular algorithm used in this research from the forced vibration tests. The empirical results are compared against the results of the calibrated finite-element model of the system from former ambient vibration tests, considering dam-reservoir-foundation interaction effects. Consistent conformity is obtained between experimental and numerical results for eight middle modes of the Dam-Reservoir-Foundation system.
\end{abstract}


Keywords: Forced vibration test, Dam-Reservoir-Foundation, Dynamic properties, Finite element method (FEM), Damping ratio, Mode shape, Shahid Rajaee arch dam

\section{Introduction}

The earthquake design and analysis of dams are one of the most important problems since their failure could result in major loss of life and cost. An integral part of any design process is numerical and analytical techniques that are used to obtain design parameters. Any analysis process is evaluated by its capability to reproduce or predict observed behavior. Dynamic properties such as natural frequencies, mode shapes and damping ratios are very important parameters in response of structures to earthquakes. Analytical techniques make some simplifications assumptions to achieve these kinds of properties. These simplifications may lead to unreasonable results because of the complexity and some uncertain parameters of the coupled system. Some uncertainties of a dam-reservoir-foundation system are: a) material property such as concrete, jointed anisotropic rock masses, sediments, and reservoir bed structure b) geometry such as topographical lines and effective mass distribution, joint's contact surfaces, foundation cavities, reservoir shape c) initial load condition, for example, noise, pore pressure, temperature, stress and boundary conditions d) actual main load estimations. Full scale dynamic tests are recognized as the most reliable method to evaluate a structure's vibration properties. Require for this kind of tests is increasing as new analysis techniques are developed to consider the complex interaction phenomena that occur in many structures and particularly in dam-reservoir-foundation systems. In fact, the performance of the state-of-the-art numerical methods used to evaluate the seismic behavior of dams can only be truly assessed by correlation with experimental results obtained on existing structures. Experimental investigations such as forced and ambient vibration tests are very useful for this end, even with a low-level excitation. There are different kinds of vibration tests, which are used to obtain the dynamic properties of the structures. Forced vibration test on the existing structures is one of the exact and assurance methods to derive the dynamic properties of structures that can legitimize the cost of this kind of tests. Most common types of the forced vibration tests are steady-state sinusoidal excitation. Applying the harmonic load on the structure for different frequencies that so-called frequency sweeping, is applied and the dam- 
reservoir-foundation response in a time domain is recorded. The dynamic properties can be achieved by processing of these responses using the Fourier transformations .

Hatano and Takahashi were the firsts who used auto correlation techniques on experimental data to obtain the vibration period of structures. They used this method to evaluate dynamic properties of concrete arch dam using data collected on the crest of the dam during the earthquake [1]. The same research was carried out by Takahashi et al. on another dam [2]. Deinum et al. carried out forced and ambient vibration tests on Emmoson arch dam and achieved dynamic properties of the dam. They used auto correlation spectrum and cross power spectrum on their works [3]. Monticello dam was subjected to the forced vibration tests in 1967 again in 1982 and 1986. The 1967 tests employed two shakers (22 KN maximum force each, $10 \mathrm{~Hz}$ maximum frequency) with radial forces either in or out of phase to excite symmetric or antisymmetric responses. Resonant frequencies and mode shapes were computed in conjunction with the early tests using an arch-cantilever model of the dam and a lumped mass of representation of the water. All computed eigen frequencies fell below the corresponding measured ones by between $12 \%$ and $19 \%$, which could be due to inaccuracy in arch-cantilever model or overestimation of the effect of the water. Two large shakers were employed (556KN maximum forces each, $30 \mathrm{~Hz}$ maximum frequencies) in 1982 tests to investigate possible non-linear effects under different level of exciting force. Variations in the total force level from $47 \mathrm{KN}$ to $437 \mathrm{KN}$ indicated no nonlinearity in either the frequency or damping of fundamental resonance [4]. The third set of forced vibration tests on the Monticello dam was carried out to investigate water compressibility effects and included measurements of dynamic water pressure at different depths. Water pressure responses peaked at frequencies close to those observed for the dam [4]. In 1990, Severn et al. conducted dynamic tests of a large arch dam along with a comparison with its mathematical model. The results were in terms of stresses and hydrodynamic pressures [5]. Furthermore, in 1994, Duron et al. presented a paper on dynamic vibration tests (including forced and ambient) on the Big-Creek dam [6]. They carried out an accurate identification process on symmetric and anti-symmetric first and second modes. It is noted that in this field, there is a contradictory discussion with respect to the Maximum Entropy Method and the results of which by no means are certain. In 1996, Loh et al. performed ambient vibration tests on the Fei Tsui dam to study the decrease of frequencies of the first two modes of the structure due 
to raising the reservoir water level [7]. In 1999, Daniell and Taylor could precisely confirm the ambient vibration tests results with modal analysis methods [8]. Darbre et al. used ambient vibration test to obtain natural frequencies of Mauvoisin dam [9]. Proulx and Paultre carried out forced vibration tests on the Outardes 3 gravity dam in northern Quebec, Canada in summer and winter conditions. The results indicated possible joint motions in hot summer conditions, which should probably be even more obvious in harsh winter conditions [10]. Forced vibration test results obtained during winter conditions clearly indicated joint motions but more importantly highlighted a change in the dynamic behavior due to the thick ice cover present during all winter [11]. Forced vibration carried out on the Emosson arch dam, on the border of France and Switzerland, during a one-year period have shed some new light on the so important dam-reservoir interaction and on the effects of the water level [12]. Several attempts have been made to identify the modal properties of Pacoima Dam since the San Fernando earthquake in 1971. Forced vibration tests were performed in July 1971, April 1980 and July/August 2002; and recordings from the 1994 Northridge and January 13, 2001, earthquakes were employed in a system identification study. In all cases, two fundamental modes were identified with symmetric and antisymmetric shapes, and the symmetric mode has the lower frequency than the antisymmetric mode. However, the natural frequencies and damping of the identified modes vary [13].

While the state-of-the-art mathematical modeling for dynamic analysis of concrete dams has advanced rapidly during the recent years, a few studies have been done with experimental tests all around the world and particularly no previous experience in Iran. In this research, the first forced vibration test on a modern concrete arch dam in Iran is performed using insufficient available equipments. Absence of efficient equipments such as an adequate number of sensors for response recording and exciters with appropriate excitation force made us to use some innovation during the test process. Classical signal processing method using different kinds of spectra such as Auto Power, Cross Power and Coherence Spectrum on the records of the forced vibration tests is used to evaluate dynamic properties of concrete arch dam. 


\section{Forced vibration tests on Shahid Rajaie arch dam}

During this research, the first forced vibration test on a dam in Iran is conducted on Shahid Rajaie double curvature concrete arch dam. The dam is located on Tajan river approximately $35 \mathrm{~km}$ South-East of Sari City, capital of Mazandaran Province (200km North-East of Tehran). Its design and construction works have been carried out between 1989 and 1997. Reservoir water level was $23 \mathrm{~m}$ below the crest during the forced vibration tests. The main specification of the dam is presented in the table.1.

Although these kinds of tests on several dams in different countries have been performed by different researchers, a non-traditional approach to forced vibration testing was adopted for the experiments on this dam. Typically tests are performed with large operating staffs and a significant amount of test equipments. The forced vibration test described here was designed so that to operate efficiently by using a minimum number of equipments which were available .

Forced vibration tests were conducted using IIEES (International Institute of Earthquake Engineering and seismology) testing facilities in the following manner:

- Two exciter units with different characteristics: one single motor and one double motor exciter unit with maximum 30 and $20 \mathrm{KN}$ exciting forces respectively were available and used. These exciters are commonly used for small structures like buildings. As these exciter units had different properties and small forces to can be used for huge structures such as dams, some electronically and mechanical device is designed and used to control synchronization of exciter's operation to make almost considerable exciting force and their operation in two in-phase and out-of phase conditions.

- Two types of response recording sensors, nine FBA-11 accelerometer and nine SS-1 seismometer: These two different sensors were used because of their availability.

- $\quad$ Six SSR-1 data acquisition system and two Portable computers

- $\quad$ Some other electronic and mechanic devices also were used . 


\subsection{Efficient arrangements of Exciter units and Sensors}

The Finite element model of Dam-reservoir-foundation corresponding to real geometry of the dam and site topography is prepared. Modal analysis of the finite-element model is carried out and all of mode shapes of the dam is represented on the plan of the dam to find the best arrangements for exciter units and sensors. From the theory aspect, the best location for exciter units is points that have maximum displacement of the structure. The points corresponding to the maximum displacement of different mode shapes are selected to be used for installation of the exciter units.

Some limitation on the dam crest such as the bridge of free spillway is considered for selection of the installation points of exciter units. This is because the bridge does not have enough integrity of the dam body and exciter forces cannot be well transferred through the dam body and consequently, unsuitable excitation of the structure can be made. To obtain enough accuracy in approximation to the mode shapes from the tests, it is necessary to have more sensors on the crest of the dam. On the other hand, the more sensors, the more cost and processing time so it is better to choose an optimum case. In this research, the optimum case for the arrangement of sensors on the crests and galleries obtained using the results of the finite-element method. At least, two locations for installing of the recording sensors around the node points of different mode shapes are specified. On the other hand, because of unavailable sufficient sensors, two different arrangements of sensors are specified and so the forced vibration tests are repeated for these two arrangements. Figure 1 demonstrates location and a general layout of the dam. Dam body layout and two different arrangements of the sensors and exciters during the tests are illustrated in figure 2. Two different kinds of exciters which are used during these tests are shown in figure 3.

Forced vibration tests has been repeated for two different arrangements of the sensors. Two different in-phase and out-of phase conditions of exciter unit's operation are used to excite corresponding symmetric and anti-symmetric modes of vibration. One of the stations selected as reference points and leave at the same position in two different arrangements. In total 18 sensors, nine FBA-11 accelerometers and nine SS-1 seismometers, are applied during these tests . 


\subsection{Forced vibration tests operation}

Two exciter units are bolted on the dam crest at the specified positions. Response recording sensors are installed and balanced on the dam crest and one gallery according to the first specified arrangements .

Preliminary tests are conducted in which a survey of the dam response is made using two different kinds of sensors on the crest. During this tests appropriate sample per second (SPS) and gain for response recording is selected 83.33 and 10 respectively. To find the efficient range of frequencies for sweeping tests a series of on-off test in-phase and out-off phase conditions with maximum frequency ( $14 \mathrm{~Hz}$ here) is carried out. In this manner, the resonant frequencies for both symmetric and antisymmetric modes can be quickly approximated. The approximated natural frequencies during the preliminary tests are used to set appropriate frequency increments during the main forced vibration tests to find exact resonant frequencies. A sample of on-off tests records and corresponding power spectrum density indicating some preliminary approximated resonant frequencies are illustrated in figure 4 . Typically, a small frequency increment, $0.1 \mathrm{~Hz}$ is used to accurate the resonant peaks. The same frequency increment is used in this research around the preliminary frequencies.

\section{Evaluation of dynamic properties using forced vibration records}

Processing algorithm of test records to evaluate natural frequencies, shape modes and damping ratios is illustrated in figure 5. Baseline correction, low and high pass filters are applied to the records. Auto-Power Spectrum Density (PSD), Cross-Power Spectrum Density (CSD) and Coherence Spectrum are used to obtain main resonant frequencies. CSD is complex function and so have real and imaginary part. Amplitude versus frequency can be used to determine natural frequencies and phase of CSD can be used in obtaining the shapes of vibration modes. Coherence spectra used to verify of obtained frequencies from PSD and CSD spectra. Coherence spectrum varies from zero to one indicating no relation and full relation respectively. A sample of different spectra for one of the records obtained from signal processing is indicated in figure 6.

To determine the mode shapes, the phase and coherency Fourier's spectra is used. Here by calculating the phase discrepancies of each point with respect to the reference station and, 
with observing the coherency spectrum, the modal displacement sign of each station point could be determined. There are cases in which the reference station does not enable obvious phase distinction and thus other stations are examined to account for a clear and meaningful phase difference and coherency with the station concerned. To determine the damping ratios at resonance frequencies, the half power method is employed. Half power method is based on displacement spectra, and so all response spectra first is converted to the displacement spectra according to the following equations.

$$
s_{\dot{x}}(f)=f^{2} s_{x}(f) \text { and } s_{\ddot{x}}(f)=f^{4} s_{x}(f)
$$

in which $f$ is frequency and $s_{\dot{x}}(f), s_{\ddot{x}}(f)$ and $s_{x}(f)$ are power spectra of velocity, acceleration and displacement respectively.

\section{Finite element analysis}

The results of forced vibration tests are compared versus to the Finite element results of the dam-reservoir-foundation system. The 8-node brick element is used for solid media, including dam and foundation. The compressive fluid element in Eulerian approach with pressure parameters is used in the reservoir domain. Modal analysis is performed by a program devised for coupled problems such as for fluid-structure interaction. The optimum properties of dam and foundation that were obtained by ambient vibration tests (had been done on this dam in before) is used for analysis. These parameters are including: $\mathrm{E}_{\mathrm{c}}=28 \mathrm{GPa}$ and $E_{f}=11 G P a$ in which $E_{c}$ and $E_{f}$ are concrete and rock foundation modulus of elasticity respectively. It is not recommended to use design values for these parameters because of uncertainties of construction and environmental condition. Also if there was no information about the ambient test results, there is a chance to do optimization process to achieve properties of the dam and foundation to make a good conformity between the results obtained by forced tests and mathematical analysis. The finite-element model of the dam-reservoirfoundation system is demonstrated in figure 7.

\section{Forced Vibration Tests results}

The natural frequencies and corresponding damping ratios, which are obtained from forced vibration tests are presented in table 2 . The results reveal that the error of approximation is 
rather large for low natural frequencies in comparison with high frequencies due to low exciting forces on low frequencies. Figure 8 indicates the results of mode shapes for dam crest and corresponding frequencies and damping ratios for both forced vibration and finiteelement methods. Good consistency between eight middle modes of the dam from forced vibration and finite element are achieved. No conformity is obtained between numerical and experimental results of the ninth mode shape. Not sufficient excitation force, inadequate numbers of recording sensors and unsuitable arrangement of sensors for this frequency are the main causes to this unconformity. Figure 9 demonstrates the mode shapes for crown cantilever of the dam and corresponding frequencies which are obtained from forced vibration test(solid line) in combination with finite element analysis (dashed line). Only one gallery was instrumented and so the results of forced vibration tests are sketched just by two points.

\section{Acknowledgements}

The authors wish to thank M.R.Mivechi, M.K.Ahmadi for their help during this research. We are very grateful for Ministry of Power, International Institute of Earthquake Engineering and Seismology (IIEES), Mahab Ghodss Consulting Engineers and Mazandaran Regional Water Company for their support and cooperation.

\section{Conclusion}

The first forced vibration test on an arch dam in Iran was performed in this research using unsatisfactory available equipments. These tests were carried out for in-phase and out-ofphase circumstances of exciter units for two arrangements of sensors. Good conformities between corresponding shape of modes are achieved for eight frequencies obtained from tests related to 5 th to 12 th vibration modes. The first four modes of vibration of the dam are not identified using forced vibration tests due to very low forces of exciters on low frequencies. To identify these low frequency's modes the ambient vibration tests were done. No corresponding mode shape is obtained by finite-element analysis to confirm for last frequency $(\mathrm{f}=13.9973)$ of forced vibration test. 
Noise per signal ratio and inadequate exciting force to excite higher-frequency modes and inappropriate arrangement of sensors and exciters for some vibration modes can be causes of this unconformity.

\section{References}

[1] Hatano, T., Takahashi, T., (1957): The Stability of an Arch Dam Against Earthquake, Tech. Rept. C-5907, Central Res. Inst. of Elec. Power.

[2] Takahashi, T., Tsutsumi, H., Mashuko ,Y.,(1959): Behaviors of Vibration of an Arch Dam, Tech. Rept. C-5905, Central Res. Inst. of Elec. Power.

[3] Deinum, P.J., Dungar, R., Ellis, B.R., Jeary, A.P., Reed, G.A.L., Severn, R.T. (1982): Vibration Tests on Emosson Arch Dam Switzerland, J. Earthquake. Engineering and Structural Dynamics, Vol.10, PP. 447-470.

[4] Hall, J.F. (1988): The Dynamic and Earthquake Behavior of Concrete Dams: Review of Experimental Behaviour and Observational Evidence, Soil Dynamics and Earthquake Engineering, 7 (2), 58-121.

[5] Severn, R.T., Taylor, C. A., Brownjohn, J. M. W., (1990): Full-Scale Dynamic Testing and Mathematical Model Validation of Dams, J. Dam Engineering, Vol.1, Issue 2, PP.101-122.

[6] Duron, Z.H., Ostrom, D.K., and Aagaard, B. (1994): Measured Steady State, Ambient, and Transient Responses of a Small Arch Dam, Journal of Dam Engineering, 4, Issue 1.

[7] Loh, C.H. and Tsu-Shiu, W. (1996): Identification of Fei-Tsui Arch Dam from both Ambient and Seismic Response Data, Journal of Soil Dynamics and Earthquake Engineering, 15, 465-483.

[8] Daniell, W.E. and Taylor, C.A. (1999): Effective Ambient Vibration Testing for Validating Numerical Models of Concrete Dams, J. Earthquake Engineering and Structural Dynamics, 28, 1327-1344.

[9] Darbre, G.R., De Smet, C.A.M., Kraemer, C. (2000): Natural frequencies measured from ambient vibration response of the arch dam of Mauvoisin, Earthquake Engineering and Structural Dynamics, 29(5), 586-577.

[10] Proulx, J., Paultre, P. (1997): Experimental and Numerical Investigation of Dam-ReservoirFoundation Interaction for a Large Gravity Dam, Canadian Journal of Civil Engineering; 24 (1), 90-105.

[11] Paultre P., Proulx, J., Carbonneau, C. (2002): An Experimental Evaluation of Ice Cover Effects on the Dynamic Behavior of a Concrete Gravity Dam, Earthquake Engineering and Structural Dynamics, 31(12), 2082-2067.

[12] Proulx, J., Paultre P., Rheault, J., Robert, Y. (2001): An Experimental Investigation of Water Level Effects on the Dynamic Behavior of a Large Arch Dam, Earthquake Engineering and Structural Dynamics, 30 (8), 1147-1166. 
[13] Alves, W. S.,(2005): Nonlinear Analysis of Pacoima Dam with Spatially Nonuniform Ground Motion, Ph.D. Thesis, California Institute of Technology ,Pasadena, California.

[14] Tarinejad, R. (2001): Assessment of Dynamic properties of concrete arch dam using forced vibration tests, M.Sc. Thesis, Tarbiat Modares University, Tehran, Iran.

[15] Mahmoud R. Mivehchi, Mohammad T. Ahmadi and Aghil Hajmomeni, (2003): Effective Techniques for Arch Dam Ambient Vibration Test: Application on Two Iranian Dams, JSEE: Summer, Vol. 5, No. 2, 23-34. 
Table 1. Shahid Rajaie Dam Specifications

\begin{tabular}{lr}
\hline Type of dam & Double curvature \\
\hline Crest length & $427(\mathrm{~m})$ \\
\hline Height & $138(\mathrm{~m})$ \\
\hline Thickness at Base & $27(\mathrm{~m})$ \\
\hline Thickness at Crest & $7(\mathrm{~m})$ \\
\hline Reservoir Volume & 191.5 million cum \\
\hline
\end{tabular}

Table 2. Frequencies and damping ratios obtained from tests for all modes

\begin{tabular}{|c|c|c|c|c|c|c|c|c|c|}
\hline Mode No. & 5 & 6 & 7 & 8 & 9 & 10 & 11 & 12 & 13 \\
\hline $\begin{array}{c}\text { Frequency }(\mathrm{Hz}) \\
\text { Test Result }\end{array}$ & 3.5807 & 5.8594 & 7.3243 & 7.8954 & 8.6263 & 10.2304 & 10.9863 & 13.0208 & 13.9973 \\
\hline $\begin{array}{c}\text { Frequency }(\mathrm{Hz}) \\
\text { FEM Result }\end{array}$ & 4.084 & "6.011 & 7.614 & 8.225 & 8.855 & 10.613 & 11.143 & 13.309 & \\
\hline Error (\%) & 14 & 2.6 & 4 & 4.2 & 2.7 & 3.8 & 1.4 & 2.2 & \\
\hline Damping (\%) & 1.12 & 1.56 & 2.3 & 2.85 & 2.03 & 3.12 & 3.25 & 2.95 & 3.32 \\
\hline
\end{tabular}


Figure 1. Location and General view of Shahid Rajaee Arch Dam

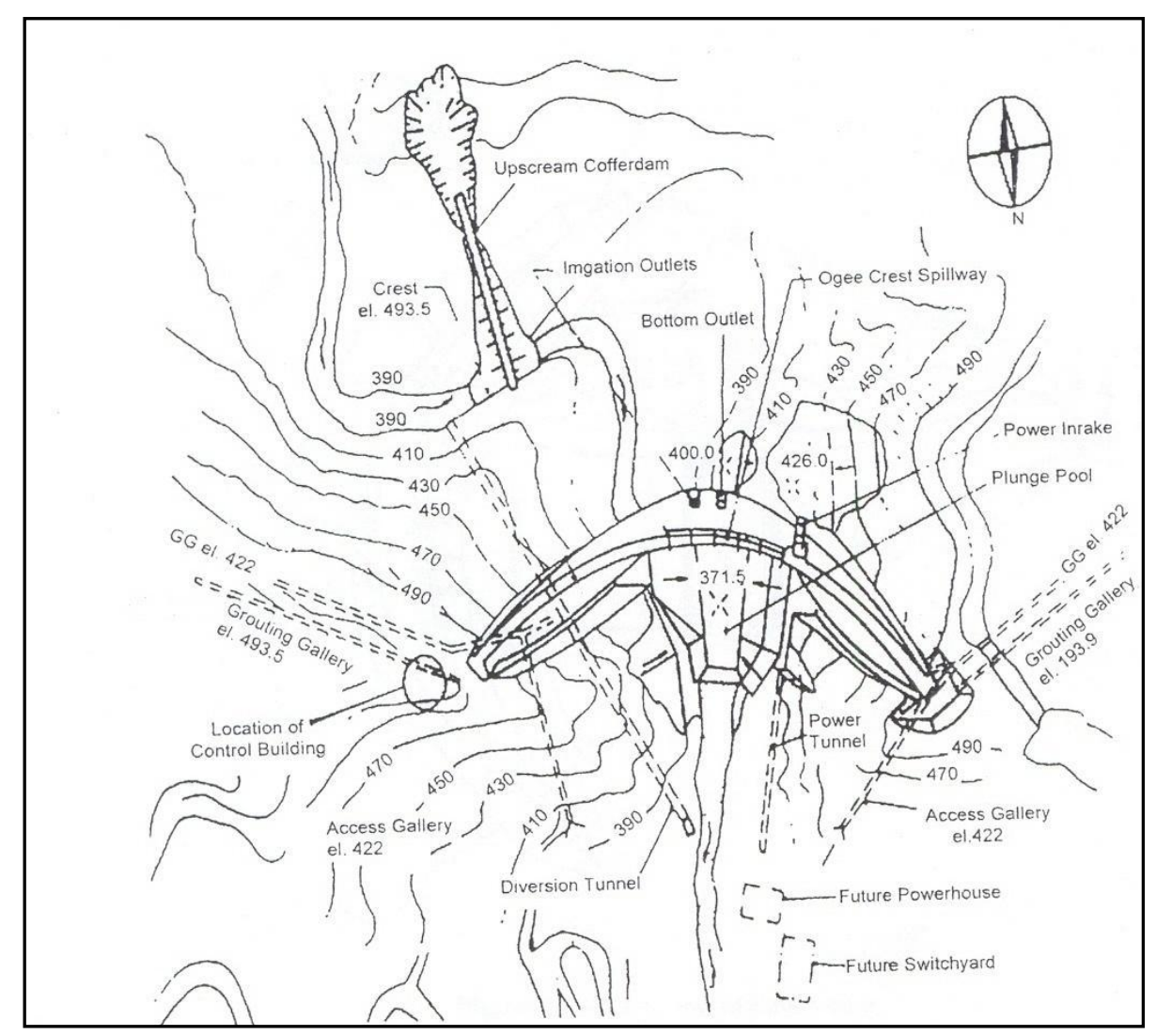


Figure 2. Arrangements of the Forced vibration test equipments

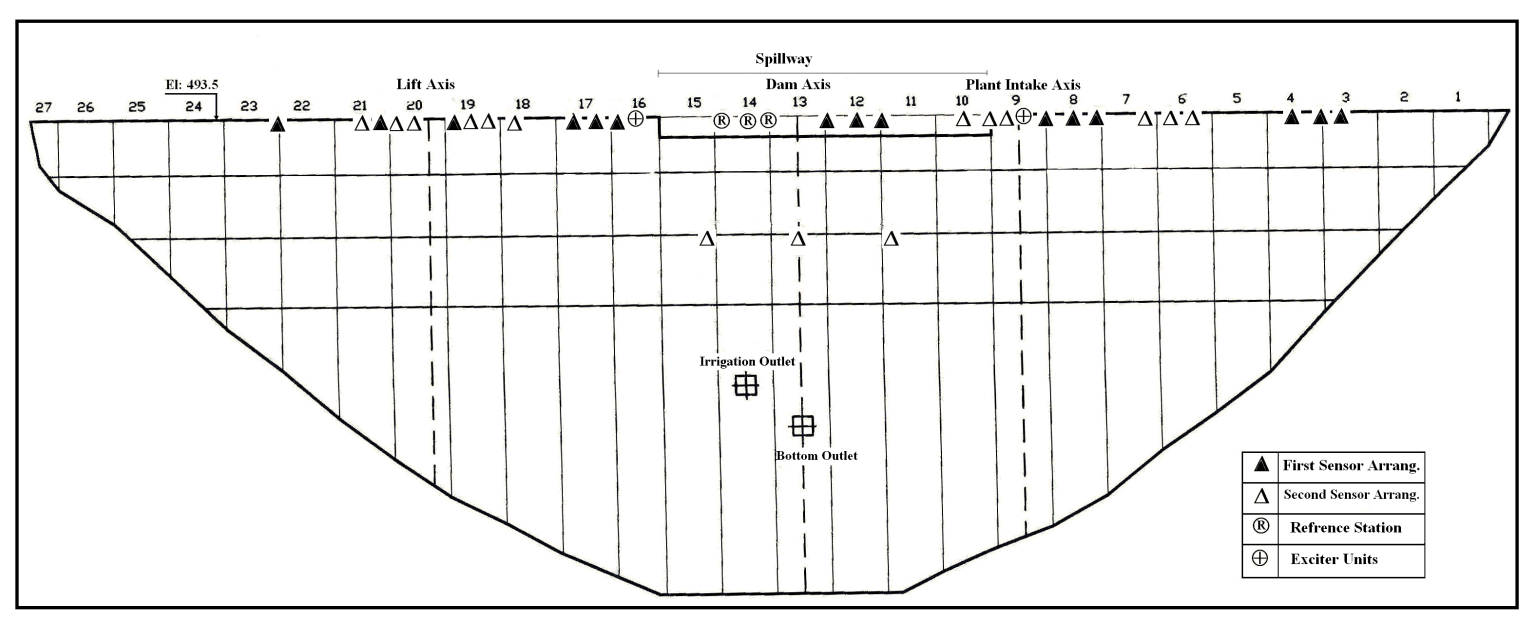


Figure 3.Two different kinds of exciters, the double motor (left) and single motor exciter (right)
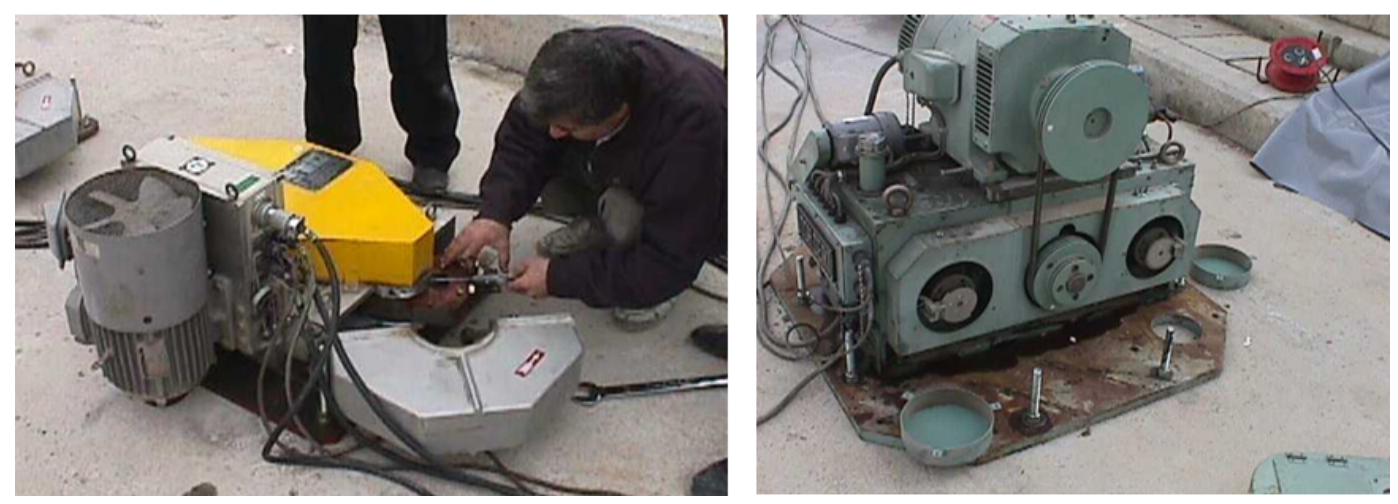
Figure 4. A sample of On-Off tests results, a) PSD of Record and Approximated Resonant frequencies , b) Time series of response record
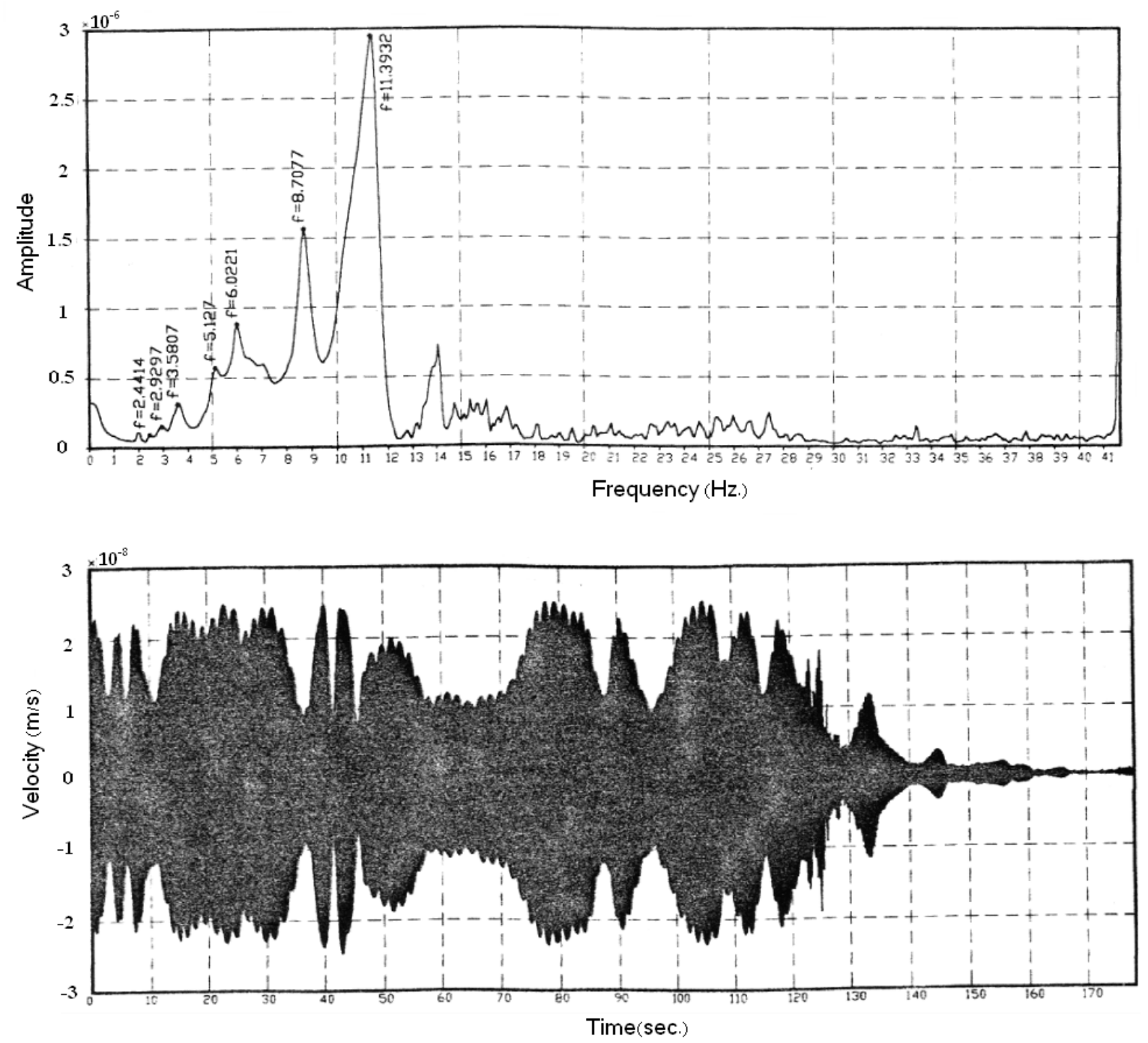
Figure 5. A sample of PSD, CSD, Coherence, Phase of CSD and recorded response time series.
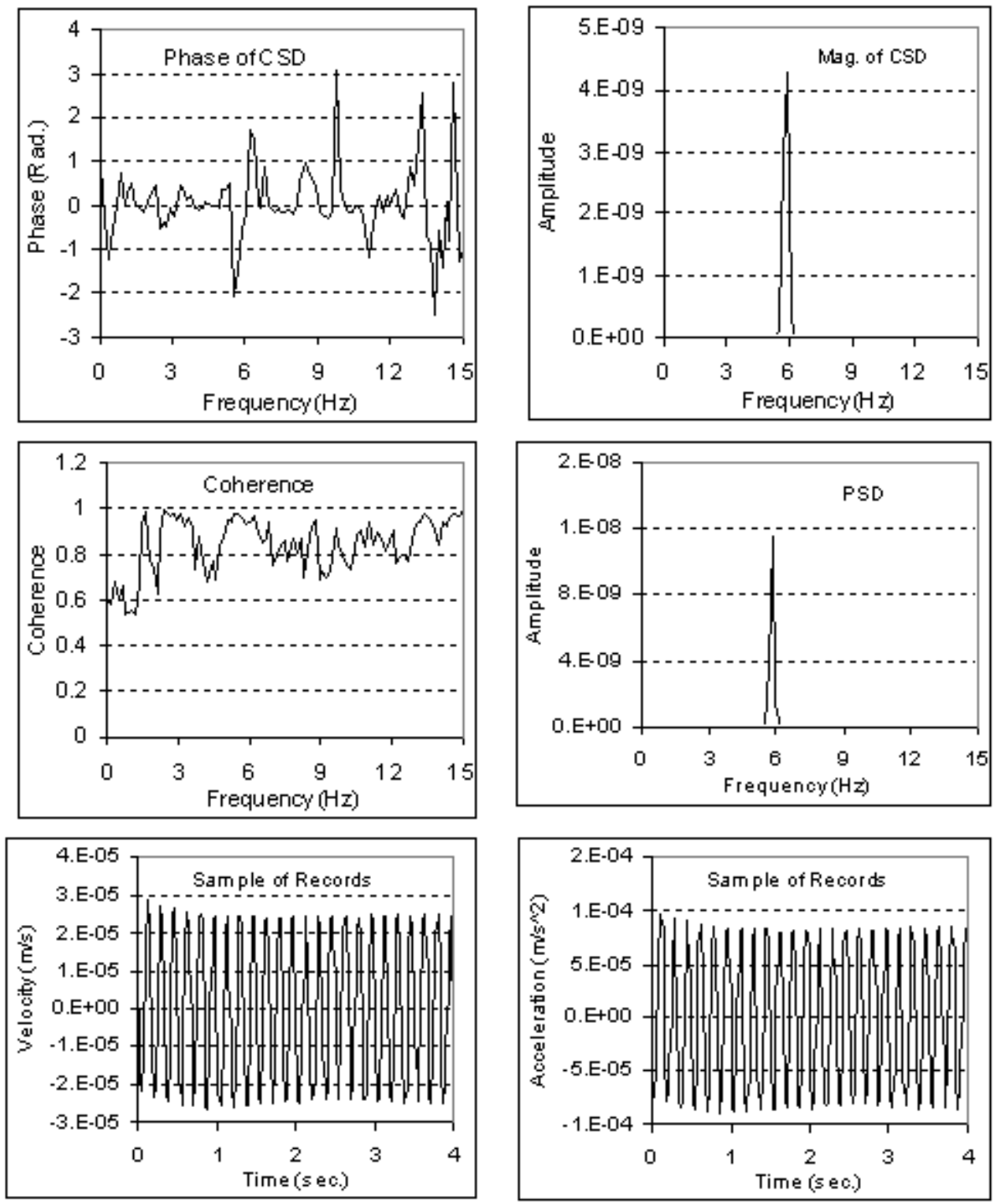
Figure 6. Flowchart of data processing on the tests records

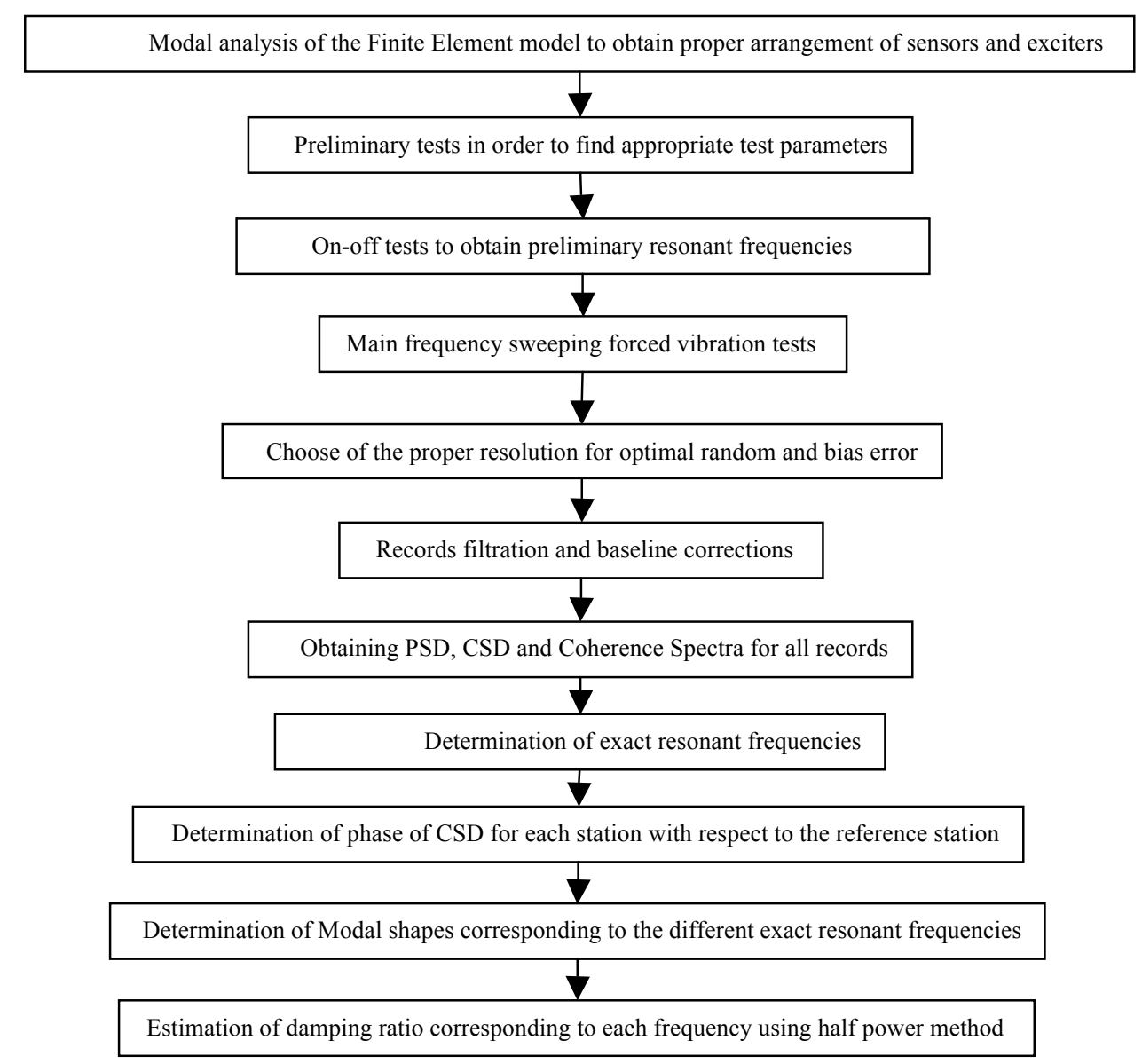


Figure 7. Finite Element model of the dam-reservoir-foundation system

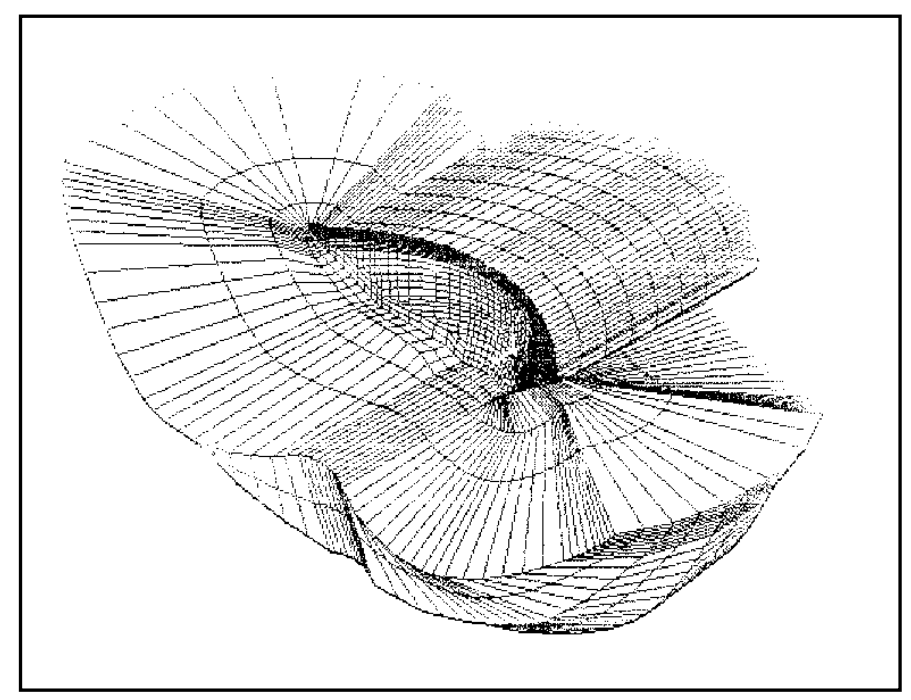


Figure 8. Comparison of the shape of modes obtained from the forced vibration test and the finite element analysis
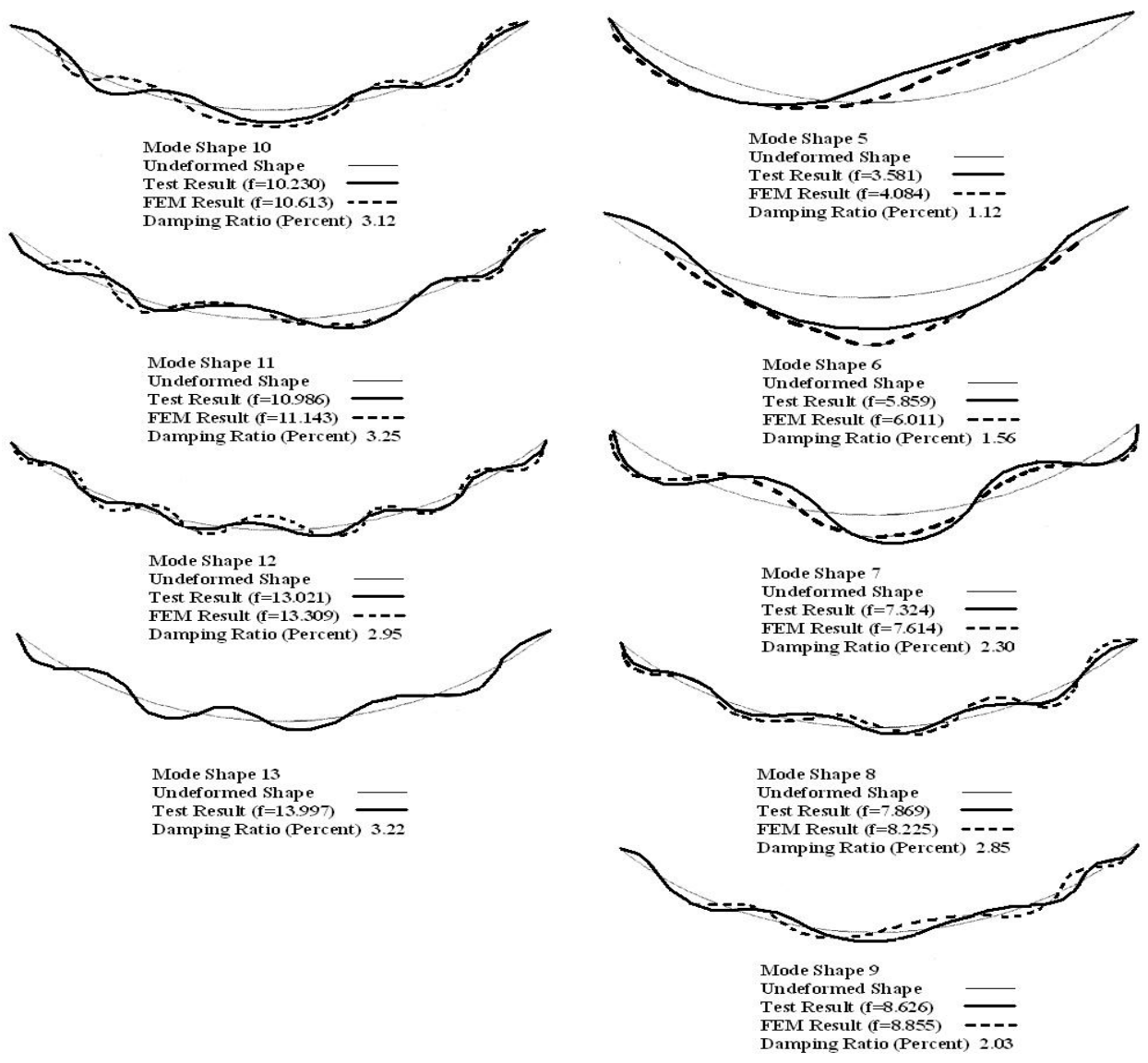
Figure 9. The mode shapes of Crown Cantilever obtained from combination of forced vibration test and the finite element analysis for different frequencies

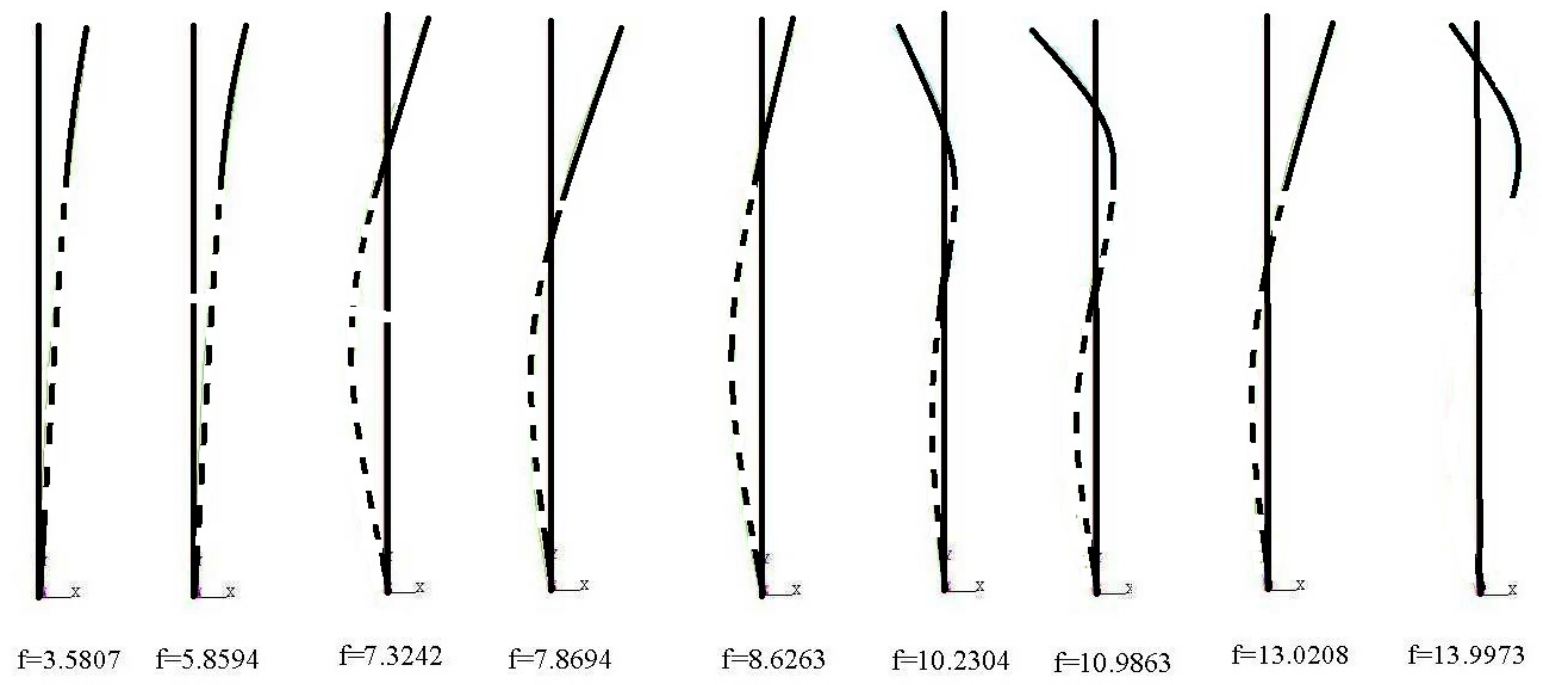

